\title{
Health and wellbeing is the most common reason for doctors to take a break from training
}

\author{
Tom Moberly UK editor
}

The BMJ

Health and emotional wellbeing is the most common reason for doctors to take a break from training, data from the GMC show. In total, $43 \%$ of doctors who took a break from training said they had done so for reasons related to their health and emotional wellbeing, while $32 \%$ cited career or specialty choice, and $26 \%$ cited their training or work environment. The results were drawn from the reasons provided to the GMC by 585 doctors who had taken a break from training and completed a survey on flexibility or taken part in interviews.

The GMC's data show that most doctors who take a break take up another medical role in the NHS. A survey of trainees shows that 57\% worked in the NHS during their training break, whether that was as a locum, in a staff grade post, in a locum appointment for training or service post, or as a clinical fellow. In total, 805 trainees provided data on what they had done during their break from training.
Around a third (35\%) had worked or volunteered abroad in medicine during their break, and $22 \%$ were undertaking further study, qualifications, or research. These reasons are not mutually exclusive as participants were able to name more than one activity that they had undertaken during their break.

Doctors are increasingly opting to take a break during training, and the proportion of doctors going directly from foundation training into specialty training has fallen steadily over recent years. In $2009,85 \%$ of those completing the foundation programme went straight into specialty training, but by 2012 this had fallen to $67 \%$. In $2017,43 \%$ of doctors completing the foundation programme went straight into specialty training. Most doctors who do not go straight into specialty training do return to medical training after taking a year or more out. Research by the GMC shows that $90 \%$ of doctors who complete foundation training do this within three years, and within five years of completing foundation training $93 \%$ of doctors have returned to UK training. 


\section{Figures}

ACTIVITIES UNDERTAKEN DURING A BREAK FROM TRAINING

The data used for these charts is based on telephone interviews, focus groups and surveys with
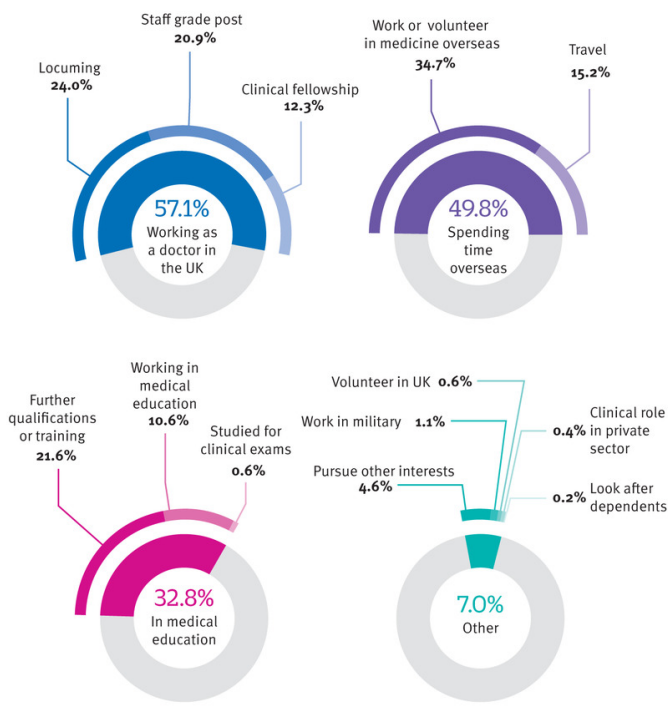

REASONS FOR TAKING A BREAK FROM TRAINING

The data used for these charts is based on telephone interviews

and surveys with 585 doctors who had taken a break from training.

Respondents could choose mutiple options.

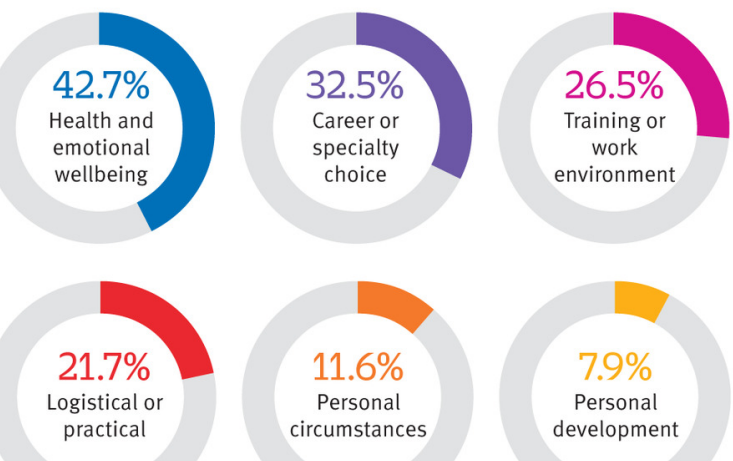

